EPiC Series in Language and Linguistics
Volume 1, 2016, Pages 216-227
CILC2016. 8th International
Conference on Corpus Linguistics

\title{
Corpus Analysis of Discourse Markers in Corporate Reports Involving Climate Change
}

\author{
Oleksandr Kapranov \\ University of Bergen, Norway \\ Oleksandr.kapranov@uib.no
}

\begin{abstract}
This article involves a corpus-assisted quantitative analysis of discourse markers (further in the article - DMs) identified in the climate change sections of corporate annual reports by British Petroleum and the Royal Dutch Shell corporations. Corporate discourse involving climate change has been amply elucidated from the linguistic macro-perspective (Koteyko, 2012; Livesey, 2002), whilst the discursive micro-perspective still receives little attention. The present corpus-assisted study seeks to elucidate corporate discourse on climate change from the micro-perspective by identifying DMs in climate change sections of annual reports by British Petroleum and the Royal Dutch Shell corporations. Additionally, the novel aspect of the present study involves a juxtaposition of the to-beidentified DMs in annual reporting by these two corporations. The corpus of the study involves climate change sections of the annual reports by British Petroleum and the Royal Dutch Shell Group within the time frame from 2010 until 2015. The corpus has been analysed in WordSmith (Scott, 2012). Results of the data analysis indicate that the most frequent DMs used in climate change discourse by British Petroleum involve and $(\mathrm{M}=4,2 \%)$, as $(0,9 \%)$, also $(\mathrm{M}=0,4 \%)$, likely $(0,3 \%)$, and but $(\mathrm{M}=0,15 \%)$, while DMs identified in the Royal Dutch Shell Group's climate change discourse comprise and $(\mathrm{M}=2 \%)$, but $(\mathrm{M}=0,15 \%)$, also $(\mathrm{M}=0,6 \%)$, such $(\mathrm{M}=0,2 \%)$, however $(\mathrm{M}$ $=0,2 \%)$, accordingly $(\mathrm{M}=0,1 \%)$, furthermore $(\mathrm{M}=0,16 \%)$, further $(\mathrm{M}=0,1 \%)$, and therefore $(\mathrm{M}=$ $0,1 \%)$. These findings are further presented and discussed in detail in the article.
\end{abstract}

\section{Key words}

Discourse markers, corporate discourse, climate change, corporate annual reports, corpus-assisted stud

\section{Introduction}

This article involves a corpus-assisted analysis of DMs identified in the climate change sections of corporate annual reports by British Petroleum (further - BP) and the Royal Dutch Shell Group (further referred to in the article as Shell). These corporations are considered to be among the leading 
international actors which simultaneously contribute to the issue of climate change by greenhouse gasses emissions and incur losses from the negative consequences of climate change. It also should be borne in mind that fossil fuels corporations, for instance, BP and Shell, are subject to international and national legislation to mitigate climate change (Asbury \& Ball, 2016). Consequently, both BP and Shell have incorporated the issue of climate change into their discourse narratives pertaining to corporate responsibility, the environment, and sustainability.

The issue of climate change is typically represented in these corporations' annual reports, official press releases, communication with the stakeholders, e.g. the Chief Executive Officer's letters to the stakeholders, and other types of corporate disclosures available to the public and to the government bodies. In linguistics and, in particular, in discourse studies, there is a growing body of research which focuses on the framing of climate change discourse by corporate actors (Koteyko et al., 2010; Livesey, 2002). Framing is defined as systematic lenses or interpretative overlays which guide communal interpretation and definition of particular issues and facilitate the labelling of the events (Miller 2000:211-212; Nisbet, 2009). The framing of climate change by the corporate actors involves 'the strategic meanings they dynamically ascribe to various climate change responses.' (Fleming et al., 2015:202). It is inferred from the current literature in linguistics and discourse studies that the corporate world frames climate change via the lenses of corporate image management, conceptual metaphors of responsibility, care and citizenship, as well as via discourse of crisis and risk management in relation to the issue of climate change (Livesey, 2001; Livesey, 2002; Talbot \& Boiral, 2015).

Building upon previous research involving corporate climate change discourse, the study further presented in this article seeks to identify DMs associated with climate change discourse by BP and Shell respectively based on the corpus of these corporations' annual reports. A corporate annual report is a major corporate endeavor, designed to construe a positive corporate image to the stakeholders, investors, state regulatory actors, financial media and the general public (Hyland, 1998:224). The climate change sections of BP's and Shell's annual reports provide these corporations' official views on the issue of climate change, its impact on business and the mitigation of the negative consequences of climate change. Presumably, DMs used in the framing of climate change discourse by these corporate actors facilitate the construal of the positive corporate image and assist in reflecting the corporate stance on the issue of climate change. The study further described in the article will attempt to verify this assumption. This study involves several novel aspects, such as a corpus-assisted identification of the most frequent DMs in corporate climate change discourse and the subsequent juxtaposition of DMs identified in climate change discourse by BP and Shell respectively. Hence, this article is structured as follows: First, previous studies involving DMs in corporate discourse will be presented. Second, previous literature involving the issues of climate change in corporate discourse will be outlined. Third, the study of DMs in the climate change sections of the corporate annual reports by BP and Shell will be presented and discussed.

\subsection{Discourse Markers in Corporate Corpus}

DMs involve linguistic items that function in cognitive, expressive, social and textual domains (Schiffrin, 2001:54). DMs constitute a diverse class of elements, typically comprising conjunctions and adverbs (Koops \& Lohman, 2015:233). Classifications of DMs vary and it is inferred from previous studies that the category is multifunctional (Dahl, 2004:1811) and defies a clear definition (Bolden, 2015:1). DMs are also referred to a variety of other names, such as discourse connectives, discourse operators, discourse particles, discourse signaling devices, phatic connectives, pragmatic expressions, pragmatic formatives, pragmatic markers, pragmatic operators, semantic conjuncts, and sentence connectives (Fraser, 1999: 932; Iseni et al., 2013:35; Schourup, 1999:227). It should be noted, however, that the term discourse marker abbreviated as $D M$ is consistently used in this article. 
From the point of view of semantics, DMs can be defined as 'linguistic items which fulfil a nonpropositional, metadiscursive (primarily connective) function, and whose scope is inherently variable, such that it may comprise both sub-sentential and supra-sentential units.' (Mosegaard Hansen, 1998:236). From a macro-semantic perspective, DMs can be regarded as textual means which contribute to the polyphony of voices in the narrative (Fløttum, 2002). For instance, DMs alongside with metadiscursive phenomena indicate the writer's presence in the text, frame the overall presentation in the written narrative and facilitate the reader's guidance throughout the narrative (Zhang, 2016).

DMs are deemed to be a complex phenomenon which involves textual, pragmatic and linguocognitive variables (Guo, 2015:70). On the textual level, DMs are used to signal discourse relations in a text segment (Eckle-Kohler et al., 2015). According to Fraser (1999:938), DMs 'impose a relationship between some aspect of the discourse segment they are part of, call it $S 2$, and some aspect of a prior discourse segment, call it S1'. Specifically, DMs are deemed to indicate sequential (Norrik, 2016:297) and cohesive relationships between the utterances (Mueller, 2005:1) and function as a 'two-place relation, one argument lying in the segment they introduce, the other lying in the prior discourse' (Fraser, 1999:938). Additionally, DMs are thought to mark either the foregrounded or backgrounded information (Brinton, 1990).

On the level of oral discourse, DMs are considered in conjunction with hesitations and fillers to allow for cognitive planning of the forthcoming utterance (Fox Tree, 2000). In oral communication, DMs are theorised to facilitate turn-taking and floor holding for the speaker (Bolden, 2015:5; Fox Tree, 2015). DMs in oral discourse are thought to indicate the speaker's perception of the process of inferencing and utterance interpretation (Andersen, 2001:79). In this sense, DMs orient the listener, but do not create meaning (Norrick, 2016:298).

In corporate discourse involving financial disclosures, the logico-semantic and interpersonal meanings encoded in DMs render them useful as rhetorical devices (Camiciottoli, 2010:651). In this regard, Hyland (1998) notes that DMs therefore and nevertheless are used in business discourse to guide the readers' attention in the direction desirable to the company's management. Hyland (1998) suggests that DMs are used by Chief Executive Officers (CEOs) to support their claims and draw the desirable conclusions. Similar findings are reported by Garzone (2005), who posits that DMs yet, although, and however are amply used in CEOs' letters to the stakeholders to facilitate a persuasive rhetorical effect.

Camiciottoli (2010:656) proposes an analysis of DMs in corporate discourse involving financial disclosures, which focuses on the following three groups of DMs: i) additive (in addition/additionally, again, similarly, likewise, moreover, furthermore, equally); ii) contrastive (however, yet, on the other hand, nevertheless, in contrast, besides, instead, even so); iii) resultative (as a result, therefore, as a consequence/consequently, thus, hence, accordingly). As indicated by Camiciottoli (2010), the most frequent DMs used in corporate discourse involving finances are however, in addition/additionally and as a result. Camiciottoli (2010) concludes that the formal register of DMs, for instance, the usage of however instead of but, is crucial to the rhetorical management in financial discourse, since it imparts a more elevated and academic style of communication by the CEOs. Following these findings, it can be assumed that those DMs, which are typically associated with the academic and formal styles, are employed by the CEOs to create an image of authority and trust in the communication with the stakeholders.

\subsection{Climate Change in Corporate Discourse by BP and Shell}

There is a substantial increase in awareness of the issue of climate change among public and corporate actors (Torcello, 2016). As far as the corporate actors are concerned, Halkos and Skouloudis (2016:22) indicate that fossil fuels corporations are significantly contributing and simultaneously are essentially exposed to the direct physical impacts of climate change but they also 
face regulatory risks from impending legislations with respect to their greenhouse gas emissions'. Consequently, fossil fuels corporations seem to recognise the importance of climate change communication and include the narrative of climate change into their corporate reporting. Research indicates that international fossil fuels corporations have become more strategic in addressing environmental and climate change issues (Higgins \& Coffey, 2016:1). An important element of the strategic approach to the issue of climate change involves corporate annual reports and corporate environmental disclosures available to the public at large, stakeholders and government agencies (Haque et al., 2016).

Corporate climate change disclosures are considered a routine practice by major international fossil fuels corporations. For instance, both BP and Shell include a Climate Change section into their annual reports. Whilst the issue of climate change does not seem to occupy a central place in fossil fuels corporations' documents, it is, nevertheless, consistently present in the annual reports by BP and Shell respectively. These sections are typically integrated into the issues of corporate responsibility, sustainability and the environment. Presumably, the embeddedness of climate change discourse into other issues is explained by the corporate actors' need 'to balance a number of competing priorities and demands about economic, social and environmental outcomes' (Higgins \& Coffey, 2016:2).

The conflation of environmental, social and climate change issues in corporate reports and disclosures has been observed by a number of researchers (Livesey, 2002). Talbot and Boiral (2015:332) posit that 'the literature on corporate disclosure on climate change generally emphasizes the importance of the corporate search for social legitimacy, the type pf communication and the specific arguments used to justify the companies' negative impacts' on the environment. The framing of the corporation as a caring actor, a caring citizen who cares for the environment and is concerned with the issue of climate change has been investigated by Livesey (2001). It has been found that Shell frames its environmental and climate change discourse via conceptual metaphors 'Shell as a Caring Corporation' and 'Shell as a Citizen' (Livesey, 2002).

Livesey (2002) argues that Shell frames the issue of climate change via conceptual metaphor 'Shell as a Citizen' to present itself as a socially and environmentally responsible corporate actor. This presentation is facilitated by the imagery of care and corporate responsibility, which metaphorically is associated with the concept of citizenship. Conceptual metaphor 'Shell as a Citizen' is further reinforced in Shell's discourse by framing Shell as a trustworthy, law-abiding citizen who is committed to sustainable development and is concerned with the issues of climate change. In conjunction with the metaphor 'Shell as a Citizen', it should be mentioned that similar metaphors have been identified in previous qualitative research involving BP (Kapranov, forthcoming). It has been found that BP, identically to Shell, frames its climate change discourse via 'BP as a Citizen' metaphor. BP's climate change discourse emphasises the role of corporate social responsibility and the corporation's care for the environment. Such framing seems pertinent to counterbalance the general public's concern involving the so-called 'dirty' fossil fuels, which exacerbate the already precarious situation concerning climate change. Both BP and Shell have experienced significant environmental disasters within the last twenty years, which have substantial negative reaction on the part of the consumers, e.g. the boycott of Shell's products after the Brent Spar incident, as well as on the part of the nongovernment organisations, e.g. the multimillion law suites to BP for the Deep Water Horizon oil spill. Hence, these corporations construe their self-image via the metaphor of environmentally-friendly citizens who prioritise climate change mitigation (Kapranov, forthcoming). 


\section{Discourse Markers in Corporate Reports Involving Climate Change: The Present Corpus-Assisted Study}

The problem of DMs in corporate discourse involving climate change is novel and has received little to no attention in previous studies. The novelty of the present research involves a corpus-assisted investigation of DMs in corporate annual reports by the major corporate actors, BP and Shell respectively. These two fossil fuels corporations have been addressing the issue of climate change in their annual reports since early 2000s. Both BP's and Shell's annual reports contain sections pertaining to the issue of climate change. Whilst these two corporations' climate change discourse has been previously elucidated from a macro-perspective (Koteyko, 2012; Livesey, 2002), there is little research on the discursive micro-level involving the framing of the issue of climate change. It is argued in this study that a corpus-assisted investigation of DMs in climate change discourse by BP and Shell would provide a nuanced and multifaceted view of how these corporate actors frame their climate change discourse. Hence, the study described below attempts to provide an outline of DMs in the climate change sections of annual corporate reports by BP and Shell.

Prior to proceeding with the present study, it seems pertinent to note that the term $D M$ has different meanings for different groups of researchers (Fraser, 1999:932). Furthermore, there are no generally accepted lists of DMs in the English language (Jucker, 1993:436). Taking this into consideration, the present study follows the definition and classification of DMs proposed by Fraser (2015:48):

.... a DM is a lexical expression, drawn from one of three classes (Contrastive DMs, Elaborative $D M s$, and Implicative DMs), which typically occurs in S2 sentence-initial position in a S1-S2 combination, and which provides no semantic content value but rather signals a semantic relationship between the two sentences.

Following Fraser (2015), contrastive DMs in this study involve but, yet, still, nevertheless, despite that, on the other hand, alternatively, on the contrary, in contrast, conversely, instead, rather. The class of implicative DMs is comprised of so, therefore, thus, then, given that, as a result, as a consequence, consequently, as a conclusion, all in all, accordingly, hence, for that reason. In accordance with Fraser (2015), the class of elaborative DMs is represented by and.

\subsection{Hypothesis and Specific Research Aims}

The hypothesis is based upon previous research which suggests that DMs are dependent on the wider discursive context in which they are used and in the pragmatic functions they fulfil (DafusMilne, 2008; Mao, 1993). Given that annual reports reveal the corporations' perspectives and standpoints (Craig \& Amernic, 2016), it is hypothesised that DMs are employed in the climate change sections of the corporate annual reports to express the corporate image in relation to the issue of climate change and to facilitate the stakeholders' comprehension of that image. Specifically, it is assumed that corporate climate change discourse would be characterised by the prevalence of DMs which are associated with implicative and elaborative relationships, whilst contrastive DMs markers would be epiphenomenal. Following this assumption, specific research aims have been formulated as follows:

i) to identify the most frequent DMs in the corpus of climate change sections of the annual reports by BP and Shell respectively;

ii) to identify the discursive strategies the most frequent DMs are associated with;

iii) to juxtapose the to-be-identified DMs in the climate change sections of the annual reports by BP with those of Shell. 


\subsection{Materials}

The materials of the present corpus-assisted study involve annual reports by BP and Shell within the timeframe 2010-2015. These annual reports are available to the public online at Www.bp.com and WWW.shell.com respectively. The total number of words in the climate change sections of the annual reports by BP is 2315, and in Shell's is 3595 respectively. All the annual reports are in English. They adhere to the genre of business discourse and are considered comparable for the purpose of this study. All the annuals reports by BP and Shell contain the sections labelled 'Climate Change'. These sections have been extracted from the body of the annual reports and subsequently analysed.

\subsection{Methods}

Quantitative methodology is employed in the study. The corpus of annual reports have been analysed quantitatively in computer program WordSmith (Scott, 2012). The program WordSmith (Scott, 2012) has been applied to each section 'Climate Change' of the respective annual report to yield the word frequency lists. In those lists, DMs have been identified in accordance with the abovementioned definition of DMs by Fraser (2015). Further classification of the identified DMs follows the methodology described in Fraser (2015).

\subsection{Results}

Quantitative analysis of the corpus in WordSmith has yielded results presented in Tables 1 - 3 respectively. Table 1 involves the total number of words per subsection 'Climate Change' in annual reports by BP and Shell respectively and is organized chronologically from 2010 until 2015. Table 2 presents descriptive statistics of DMs frequencies in annual reports by BP. Table 3 involves descriptive statistics of DMs frequencies in annual reports by Shell.

\begin{tabular}{|c|c|c|}
\hline Year & BP & Shell \\
\hline $\mathbf{2 0 1 0}$ & 214 & 571 \\
\hline $\mathbf{2 0 1 1}$ & 530 & 522 \\
\hline $\mathbf{2 0 1 2}$ & 482 & 579 \\
\hline $\mathbf{2 0 1 3}$ & 360 & 1150 \\
\hline $\mathbf{2 0 1 4}$ & 291 & 673 \\
\hline $\mathbf{2 0 1 5}$ & 438 & 1100 \\
\hline
\end{tabular}

Table 1: Total number of words per subsection 'Climate Change' in annual reports by BP and Shell.

\begin{tabular}{|l|l|}
\hline Year & DMs \\
\hline $\mathbf{2 0 1 0}$ & And $(4.3 \%)$, as $(0.8 \%)$, also $(0.5 \%)$, but $(0.5 \%)$ \\
\hline $\mathbf{2 0 1 1}$ & And $(5.1 \%)$, as $(0,9 \%)$, also $(0,2 \%)$ \\
\hline $\mathbf{2 0 1 2}$ & And $(3,9 \%)$, as $(0,9 \%)$, likely $(0,3 \%)$ \\
\hline $\mathbf{2 0 1 3}$ & And $(4,6 \%)$, as $(0,9 \%)$, also $(0,5 \%)$ \\
\hline $\mathbf{2 0 1 4}$ & And $(3,8 \%)$ \\
\hline $\mathbf{2 0 1 5}$ & And $(3,4 \%)$, also $(0,4 \%)$, but $(0,3 \%)$ \\
\hline
\end{tabular}

Table 2: Descriptive statistics of DMs frequencies in annual reports by BP from 2010 till 2015. 


\begin{tabular}{|l|l|}
\hline Year & DMs \\
\hline $\mathbf{2 0 1 0}$ & And $(3 \%)$, as $(1 \%)$, also $(0,4 \%)$, such $(0,2 \%)$, but $(0,2 \%)$ \\
\hline $\mathbf{2 0 1 1}$ & And $(3 \%)$, as $(1,2 \%)$, also $(0,2 \%)$, in addition $(0,2 \%)$ \\
\hline $\mathbf{2 0 1 2}$ & $\begin{array}{l}\text { And }(0,7 \%) \text {, as }(0,3 \%) \text {, also }(0,2 \%) \text {, however }(0,2 \%) \text {, in addition }(0,2 \%), \\
\text { furthermore }(0,2 \%)\end{array}$ \\
\hline $\mathbf{2 0 1 3}$ & And $(1,6 \%)$, as $(0,4 \%)$, furthermore $(0,1 \%)$, also $(0,2 \%)$, but $(0,1 \%)$ \\
\hline $\mathbf{2 0 1 4}$ & \begin{tabular}{l} 
And $(2,3 \%)$, as $(0,6 \%)$, in addition $(0,1 \%)$, further $(0,1 \%)$, furthermore $(0,1 \%)$ \\
\hline $\mathbf{2 0 1 5}$
\end{tabular} $\begin{array}{l}\text { And }(2,8 \%), \text { also }(0,5 \%) \text {, however, }(0,2 \%) \text {, as }(0,2 \%) \text {, therefore }(0,1 \%), \\
\text { accordingly }(0,1 \%)\end{array}$ \\
\hline
\end{tabular}

Table 3: Descriptive statistics of DMs frequencies in annual reports by Shell from 2010 till 2015.

\subsection{Discussion}

As seen from Table 1, the most frequent DMs in BP's annual reports within the timeframe 20102015 involve and $(\mathrm{M}=4,2 \%)$, as $(0,9 \%)$, also $(\mathrm{M}=0,4 \%)$, likely $(0,3 \%)$, and but $(\mathrm{M}=0,15 \%)$. The corpus of Shell's climate change discourse involves the following DMs and $(\mathrm{M}=2 \%)$, as $(\mathrm{M}=$ $0,6 \%)$, also $(\mathrm{M}=0,6 \%)$, such $(\mathrm{M}=0,2 \%)$, however $(\mathrm{M}=0,2 \%)$, accordingly $(\mathrm{M}=0,1 \%)$, furthermore $(\mathrm{M}=0,16 \%)$, further $(\mathrm{M}=0,1 \%)$, and therefore $(\mathrm{M}=0,1 \%)$. These data seem to support the hypothesis, where it has been assumed that corporate climate change discourse would be characterised by the prevalence of DMs which are associated with implicative and elaborative relationships, whilst contrastive DMs would be epiphenomenal. The data presented in Table 2 indicate that contrastive DMs are not amongst the most frequent in BP's climate change discourse. Judging from the data, climate change discourse by BP is characterised by the elaborative DM marker and. Similar findings are reported in Ho (2016), who has found the prevalence of DM and in official policy documents. As indicated by the data (see Table 2), BP's climate change discourse in 2010-2015 seems to be consistently marked by the presence of the elaborative DM and:

(1) Climate change is a major global issue - one that justifies precautionary action and represents a significant challenge for society, the energy industry, and $B P . .$. We have not included any emissions from the Gulf of Mexico incident and the response effort due to our reluctance to report data that has such a high degree of uncertainty. (BP, 2010).

(2) Climate change represents a significant challenge for society, the energy industry and BP. In response to the challenges and opportunities, BP is taking a number of practical steps, including investing in lower-carbon energy products such as biofuels and wind, and ventures focused in sustainable energy solutions; and seeking to manage our own GHG emissions through a focus on operational energy efficiency, reductions in flaring and venting and the engineering design for new projects. (BP, 2011).

(3) Climate change represents a significant challenge for society and the energy industry, including BP. (BP, 2012).

In excerpts (1) - (3), one of the pragmatic functions which DM and fulfils is the facilitation of the effect of inclusiveness. BP frames itself in (1) - (3) as an equal and constitutive part of the energy sector, which, in turn, is a part of society, for instance '... a significant challenge for society, the energy industry, and BP' (BP, 2010); ' $a$ significant challenge for society, the energy industry and $B P$ (BP, 2011); a significant challenge for society and the energy industry, including BP. (BP, 2012). Presumably, DM and in these instances facilitates the effect of BP as a partner, an integral part in the triangle 'society - energy sector - BP', which every actor in this triangle being concerned by the challenged posed by climate change. These findings are evocative of previous research (Livesey, 2002), which indicates that fossil fuels corporations tend to present their self-image as a metaphoric 
citizen, as a part of society. Consequently, as a part of society and a citizen, BP positions itself as one among many other societal parts, which are concerned with the issue of climate change.

However, in excerpts (4) - (6) below DM and plays a purely additive, elaborative role. For instance, the additive effects of the measures to mitigate climate change by BP as seen as 'to incorporate energy use considerations in their business plans and to assess, prioritize and implement technologies and systems to improve energy usage.' (BP, 2013):

(4) We also require our operations to incorporate energy use considerations in their business plans and to assess, prioritize and implement technologies and systems to improve energy usage. (BP, 2013).

(5) ... we require our operations to incorporate energy use considerations in their business plans and to assess, prioritize and implement technologies and systems that could improve usage. We factor a carbon cost into our own investments and engineering designs for large new projects, and invest in lower-carbon energy products. (BP, 2014).

(6) There is a growing number of emission pricing schemes globally, including in Europe, California and China, additional monitoring regulations in the US, and more focus on reducing flaring and methane emissions in many jurisdictions. (BP, 2015).

Similarly to BP, in Shell's climate change discourse DM and is used most frequently. However, comparing to BP, its mean values are lower, e.g. Shell $(\mathrm{M}=2 \%)$ and $\mathrm{BP}(4,2 \%)$. This finding supports research by Camiciottoli (2010:656) who suggests that DMs in corporate reports seems to be standardised. More support to this suggestion is given by the data presented in Table 3. As evident from the data, Shell's climate change discourse does not appear to extensively employ contrastive DMs, for instance the frequency of DM but $(\mathrm{M}=0,15 \%)$ in Shell's climate change section of the reports within 2010-2015 is equal to BP's usage of DM but within the same time frame, namely M = $0,15 \%$.

Further support for the tendency towards standartisation of climate change discourse by fossil fuels corporations is provided by DM as. As in the case of DMs in climate change sections of annual reports by BP, DM as (M = 0,6\%) appears to be the second most used DM after and in the 2010, 2013 and 2014 annual reports by Shell:

(7) The management of carbon dioxide (CO2) emissions - the most significant greenhouse gas (GHG) - will become increasingly important as concerns over climate change lead to tighter environmental regulations. (Shell, 2010).

(8) The management of emissions of carbon dioxide (CO2) will become increasingly important as concerns over climate change lead to tighter environmental regulation. (Shell, 2013)

(9) As energy demand increases and easily accessible oil and gas resources decline, we are developing resources that require more energy and require advanced technology to produce. As our production becomes more energy intensive, we expect there will be an associated increase in the direct CO2 emissions from the Upstream facilities we operate. (Shell, 2014).

However, in the climate change section of Shell's 2012 annual report, DMs as and where are the second most frequent DMs:

(10) The majority of this flaring takes place at facilities where there is no infrastructure to capture the gas produced with oil, known as associated gas. Most of the continuous flaring takes place in Nigeria, where the security situation and lack of partner funding had previously slowed progress on projects to capture associated gas. (Shell, 2012). 
As seen from excerpts (7) - (10), DM as is associated with rationalising a decision and a process involved in climate change mitigation. Furthermore, DM as seems to be used in predicting positive results of the measure pertaining to the climate change mitigation. These findings are in concert with the mixed methods study by Camiciottoli (2010:658), who indicates that the usage of DM as constitutes an important rhetorical strategy by corporate writers 'to persuade their audiences of the overall soundness and good business practices of their companies.'.

Concurrently with the present findings, which are suggestive of a certain standartisation in the usage of DMs in climate change discourse by international fossil fuels corporations, it should be noted that Shell's DMs in climate change discourse appear to be more varied in comparison with BP's. Specifically, as seen from Table 3, DMs in Shell's climate change discourse involve such $(\mathrm{M}=0,2 \%)$, however $(\mathrm{M}=0,2 \%)$, accordingly $(\mathrm{M}=0,1 \%)$, furthermore $(\mathrm{M}=0,16 \%)$, further $(\mathrm{M}=0,1 \%)$, and therefore $(\mathrm{M}=0,1 \%)$. A more varied usage of DMs in climate change section is provided by the 2015 annual report in excerpt (11) below:

(11) Accordingly, we have also evaluated the resilience of our portfolio using our own business-case model that assumes an average global temperature increase of 2-3 C by 2100.... While our model assumes lower overall regulatory costs associated with our CO2 emissions in 2030 than the IEA estimate of 100/tonne, we also expect lower oil and gas prices, which projects a less positive outcome than under the IEA's 450 Scenario.

Data presented in Table 3 suggests that Shell's framing of climate change discourse involves contrastive DMs. It should be mentioned that the usage of but $(0,15 \%)$ appears to be less prominent in comparison with however $(\mathrm{M}=0,2 \%)$. Apparently, Shell's climate change discourse tends to be charaterised by elevated and formal style. This observation is supported by other DMs which are typically associated with formal writing, for instance, accordingly $(\mathrm{M}=0,1 \%)$, furthermore $(\mathrm{M}=$ $0,16 \%)$, further $(\mathrm{M}=0,1 \%)$, and therefore $(\mathrm{M}=0,1 \%)$. These findings are suggestive of an endeavor on the part of Shell to impart the image of a corporation which prioritises scientific and formal registers in its corporate narratives involving climate change. Arguably, the formality in the choice of DMs (e.g. , accordingly, furthermore, further, therefore) should foreground Shell's authoritative and, perhaps, trustworthy voice on the issue of climate change. This observation seems to be supported by Camiciottoli (2010) who posits that a formal register in the choice of DMs serves the purpose of imparting a logical, authoritative and persuasive voice in the corporation's communication with the stakeholders and the general public.

\section{Conclusions}

This article involves a corpus-assisted analysis of discourse makers in the climate change sections of corporate annual reports by fossil fuels corporations BP and Shell. The corpus involves these corporations' climate change sections of the annual reports from 2010 until 2015 respectively. The corpus has been analysed quantitatively in WordSmith (Scott, 2012) to identify the most frequent DMs in the climate change sections of the above-mentioned annual reports. It has been found that the most frequent DMs used in climate change discourse by British Petroleum involve and $(\mathrm{M}=4,2 \%)$, as $(0,9 \%)$, also $(\mathrm{M}=0,4 \%)$, likely $(0,3 \%)$, and but $(\mathrm{M}=0,15 \%)$, while DMs identified in the Royal Dutch Shell Group's climate change discourse comprise and $(\mathrm{M}=2 \%)$, but $(\mathrm{M}=0,15 \%)$, also $(\mathrm{M}=$ $0,6 \%)$, such $(\mathrm{M}=0,2 \%)$, however $(\mathrm{M}=0,2 \%)$, accordingly $(\mathrm{M}=0,1 \%)$, furthermore $(\mathrm{M}=0,16)$, further $(\mathrm{M}=0,1 \%)$, and therefore $(\mathrm{M}=0,1 \%)$.

The results of the data analysis support the hypothesis, where it has been assumed that climate change discourse by fossil fuels corporations would be characterised by the prevalence of DMs which 
are associated with implicative and elaborative relationships, whilst contrastive DMs would be epiphenomenal. Specifically, it has been established that the elaborative DM and in BP's discourse facilitates the effect of BP as a partner, an integral part in the triangle 'society - energy sector - BP', with every actor in this triangle being concerned by the challenged posed by climate change. Similarly to BP, the elaborative DM and has been identified in Shell's climate change discourse. These findings lend support to previous research (Ho, 2016), which reports the prevalence of the elaborative DM and in official policy documents.

It has been established in this research that climate change discourse by Shell is characterised by a certain degree of formality in the choice of DMs (e.g., accordingly, furthermore, further, therefore). These DMs are used by Shell in framing the corporation as an authoritative and trustworthy voice on the issue of climate change. It can be observed from the present data that the implicative DM as is associated with rationalising a decision and a process involved in climate change mitigation. The implicative DM as seems to be used in the discourse by both BP and Shell as a rhetorical strategy to impart to the stakeholders the overall positive, yet formal and persuasive practices of climate change mitigation.

\section{Acknowledgments}

I acknowledge research funding from the Norwegian Research Council and the University of Bergen within the framework of the LINGLIM project.

\section{References}

Asbury, S., \& Ball, R. (2016). The Practical Guide to Corporate Social Responsibility: Do the Right Thing. Routledge.

Andersen, G. (2001). Pragmatic markers and sociolinguistic variation: A relevance-theoretic approach to the language of adolescents (Vol. 84). John Benjamins Publishing.

Bolden, G. (2015). Discourse Markers. In Karen Tracey (ed.) The International Encyclopedia of Language and Social Interaction (pp.1-7).

Brinton, L.J. (1990). The development of discourse markers in Enlgish. In J.Fisiak (ed.), Historical Linguistics and Philology (pp.45-71). Berlin: Mouton de Gruyter

Camiciottoli, B. C. (2010). Discourse connectives in genres of financial disclosure: Earnings presentations vs. earnings releases. Journal of Pragmatics, 42(3), 650-663.

Craig, R. \& Amernic, J. (2016). Are there Language Markers of Hubris in CEO Letters to Shareholders? Journal of Business Ethics, 0, 1-14.

Dafouz-Milne, E. (2008). The pragmatic role of textual and interpersonal metadiscourse markers in the construction and attainment of persuasion: A cross-linguistic study of newspaper discourse. Journal of Pragmatics, 49, 95-113.

Dahl, T. (2004). Textual metadiscourse in research articles: a marker of national culture or of academic discipline? Journal of Pragmatics, 36, 1807-1825.

Eckle-Kohler, E., Kluge,R., \& I. Gurevych. (2015). On the Role of Discourse Markers for Discriminating Claims and Premises in Argumentative Discourse. Proceedings of the 2015 Conference on Empirical Methods in Natural Language Processing (pp.22236-2242). Lisbon: ACL.

Fleming, A., Rickards, L., A.-M. Dowd (2015). Understanding convergence and divergence in the framing of climate change responses: An analysis of two wine companies. Environmental Science \& Policy, 51, 202-214. 
Fløttum, K. (2002). La polyphonie dans une perspective macro-semantique. In H.L. Andersen, H. Nølke (Eds.) Macro-syntaxe et macro-semantique (pp.337-359). Bern: Peter Lang.

Fox Tree, J. E. (2015). Discourse markers in writing. Discourse Studies, 17 (1), 64-82.

Fraser, B. (1999). What are discourse markers? Journal of Pragmatics, 31, 931-952.

Fraser, B. (2015). The combining of Discourse Markers - A beginning. Journal of Pragmatics, 86, 48-53.

Garzone, G. (2005). Pragmatic and discoursal features of annual executive letters: observations on the rhetorical and evaluative function of concessive constructions. In: Bondi, M., Maxwell, N. (eds.) Cross-cultural Encounters: Linguistic Perspectives (pp.130-141). Rome: Officina Edizioni.

Guo, F. (2015). A Review of Discourse Markers from the Functional Perspective. Journal of Arts and Humanities, 4 (4), 69-75.

Halkos, G. \& Skouloudis, A. (2016). Exploring the current status and key determinants of corporate disclosure on climate change: Evidence from the Greek business sector. Environmental Science \& Policy, 56, 22-31.

Haque, S., Deegan, C., \& Inglis, R. (2016). Demand for, and impediments to, the disclosure of information about climate change-related corporate governance practices. Accounting and Business Research, 1-45.

Higgins, C., \& Coffey, B. (2016). Improving how sustainability reports drive change: a critical discourse analysis. Journal of Cleaner Production, 0, 1-12.

Ho, V. (2016). Discourse of persuasion: a preliminary study of the use of metadiscourse in policy documents. Text \& Talk, 36 (1), 1-21.

Hyland, K. (1998). Exploring Corporate Rhetoric: Metadiscourse in the CEO's Letter. The Journal of Business Communication, 35(2), 224-245.

Iseni, A., Almasaeid, A., \& Younes, M.A.B. (2013). The Role of Discourse Markers and Cohesive Devices in Writing: EFL Students, a Case Study. Anglisticum Journal, 2(4), 35-48.

Jucker, A. (1993). The discourse marker well: A relevance-theoretical account. Journal of Pragmatics, 19, 435-452.

Kapranov, O. (forthcoming). Do International Corporations Speak in One Voice on the Issue of Global Climate Change: The Case of British Petroleum and The Royal Dutch Shell Group. In C.Can, A. Kilimci, K. Papaja and O. Emiroglu (eds.) Global Perspectives on Social Sciences and Humanities. Theory \& Practice. Warsaw: LIF.

Koops, C. \& Lohman, A. (2015). A quantitative approach to the grammaticalization of discourse markers. Evidence from their sequencing behavior. International Journal of Corpus Linguistics, 20 (2), 232-259.

Koteyko, N., Thelwall, M. \& Nerlich, B. (2010). From Carbon Markets to Carbon Morality: Creative Compounds as Framing Devices in Online Discourses on Climate Change Mitigation. Science Communication 32 (1), 25-54.

Koteyko, N. (2012). Managing carbon emissions: A discursive presentation of 'market-driven sustainability' in the British media. Language \& Communication 32(1), 24-35.

Livesey, S.M. (2001). Eco-identity as discursive struggle: Royal Dutch/Shell, Brent Spar, and Nigeria. The Journal of Business Communication, 38, 58-91.

Livesey, S.M. (2002). Global Warming Wars: Rhetorical and Discourse Analytic Approaches to Exxonmobil's Corporate Public Discourse. Journal of Business Communication, 39, 117-146.

Louwerse M., \& Mitchell, H. (2003). Toward a Taxonomy of a Set of Discourse Markers in Dialog: A Theoretical and Computational Linguistic Account. Discourse Processes, 35(3), 199-239.

Mao, L.R. (1993). I conclude not: toward a pragmatic account of metadiscourse. Rhetoric Review, 11 (2), 265-289.

Miller, C.A. (2000). The dynamics of framing environmental values and policy: four models of societal processes. Environmental Values, 9, 211-233. 
Mosegaard Hansen, M.-B. (1998). The semantic status of discourse markers. Lingua, 104, 235260.

Müller, S. (2005). Discourse Markers in Native and Non-native English Discourse. Amsterdam/Philadelphia: John Benjamins.

Nisbet, M. C. (2009). Communicating Climate Change: Why Frames Matter for Public Engagement. Environment: Science and Policy for Sustainable Development, 51 (2), 12-23.

Norrik, N.R. (2016). Discourse Markers in Oral Narrative. In A. Capone, J.L. Mey (eds.), Interdisciplinary Studies in Pragmatics, Culture and Society (pp.297-319). Switzerland: Springer.

Schiffrin, D. (2001). Discourse markers: language, meaning, and context. The handbook of discourse analysis, 1, 54-75.

Schourup, L. (1999). Discourse markers. Lingua, 107(3), 227-265.

Scott, M. (2012). WordSmith Tools version 6, Stroud: Lexical Analysis Software.

Talbot, D. \& Boiral, O. (2015). Strategies for Climate and Impression Management: A Case Study Among Canada's Large Industrial Emitters. Journal of Business Ethics, 132, 329-346.

Torcello, L. (2016). The Ethics of Belief, Cognition, and Climate Change Pseudoskepticism: Implications for Public Discourse. Topics in Cognitive Sciences, 8, 19-48.

Zhang, M. (2016). A multidimensional analysis of metadiscourse markers across written register. Discourse Studies, 0, 1-19. 